\title{
Influence of in situ biological activity on the vertical profile of pre-emergence herbicides in sediment
}

\author{
Damien A. Devault, ${ }^{*}$ Sébastien Delmotte, Georges Merlina, Puy Lim, Magali Gerino and Eric Pinelli
}

\author{
Received 21st November 2008, Accepted 4th March 2009 \\ First published as an Advance Article on the web 26th March 2009 \\ DOI: $10.1039 / b 820793 c$
}

\begin{abstract}
The in situ effect of biological activity on herbicide degradation was studied in sediment. Early diagenesis indicators of organic matter $(\mathrm{OM})$ was selected to provide information on the presence and the kinetics of the various biotic and abiotic processes involved in the degradation of fresh organic matter, the vector of herbicides in sediment. Two tandem-coring samples were taken in the Malause reservoir, one in the hyperoxic zone (Tarn confluence, MT core) and the other in the central part, under the exclusive influence of the Garonne River (MG core), after having crossed a zone where the high intensity of abiotic processes is proven. At each site, analysis of the vertical profile of the herbicides was coupled with compounds associated with early diagenesis of OM. The MT core proved nearly seven times more contaminated than the MG core. DEA played a minor role in sediment contamination. Biological activity only seems to influence herbicide degradation indirectly. Neither oxygen concentration nor the level of labile carbon indicated any correlation between the consumption of fresh organic matter and substrate degradation. Herbicide transformation thus does not seem to depend on the consortia studied but on physicochemical parameters such as hydrolysis, leading to the long half-life of herbicides in sediment and hence their long-term presence in the aquatic environment.
\end{abstract}

\section{Introduction}

Contamination of the environment by pesticides is an increasing concern for health authorities with the generalization of pesticide use and the accumulation of evidence that contradicts the alleged harmlessness of these modern molecules. If the environmental fate of certain pesticides (especially organochlorines) is well known ${ }^{1}$ because suitable methods exist to study them, others have not yet been studied. A protocol was designed in $2007^{2}$ to assay pesticides that are more recent and less persistent in sediment than persistent organic pollutants (POPs).

The aquatic environment is known to be one of the most vulnerable $^{3}$ because of its trophic net complexity and the converging position of rivers for watershed contaminants dissolved or associated with particles. Sediment is well known to be an integrative matrix. ${ }^{4}$ Sediment could be a matrix sequestering contaminants until complete degradation preventing biota or a chronic contamination source for surface water biota, expanding intermittent contamination. For organochlorines, known for their environmental harmfulness, sediment is a proven expanding factor, allowing a non-acute toxic pesticide event to degenerate into a biomagnification event. ${ }^{5}$ Organochlorines have been banished since 1972 in the United States and France even if they are still in use in tropical countries. Their decreasing contamination over time is observed in cores

Laboratoire d'Ecologie Fonctionnelle ECOLAB UMR 5245 CNRS-UPS-INPT, Ecole Nationale Supérieure Agronomique de Toulouse, Institut National Polytechnique, Avenue de l'Agrobiopole, BP 32607, Auzeville Tolosane, 31326 Castanet-Tolosan Cedex, France. E-mail: damien.devault@wanadoo.fr; Tel: +336-84-05-09-90 taken in soil, ${ }^{6}$ sediment, ${ }^{7}$ and ice. $^{8}$ However, pre-emergence herbicides are not. Herbicides are the most popular pesticides (49\% of total consumption during 2006, essentially in developed countries, Union des Industries de la Protection des Plantes (UIPP) data). Herbicides are modern molecules profiled to have limited environmental persistence. ${ }^{1}$ However, the lack of an adapted protocol cannot ensure this. Recently developed, one protocol $^{2}$ could confirm or invalidate the limited persistence of these modern molecules using coring techniques.

Coring is an old but common exploration method. Matrixes used for coring should grow regularly by deposition, accretion or surface development and have significant longevity: inorganic as sediment or snow, organic as wood, dentin, or coral. The molecule studied is gradually internalised during growth, proportionally to its presence at the time of its internalisation. Coring provides information on the local historical exposure level (for metals ${ }^{9}$ ) and the persistence of temporary content as radionuclides $^{10}$ or POPs. ${ }^{11}$

Deposition of suspended matter potentially contaminated in areas of calm water leads to the formation of sediment, making it possible to investigate the fate of pesticides in the environment over time by coring. Indeed, surface sediment is excavated by the benthic population and is home to microbial fauna and flora, increasing spontaneous transformations (e.g. hydrolysis, desorption). Pesticide persistence could be influenced by biota directly through biodegradation or indirectly through sorption modification caused by microbial respiration metabolites. ${ }^{12}$ However, the vertical distribution of benthic biotope members depends on substrate respiration/electron acceptors. ${ }^{13}$ Electron acceptors become less and less abundant with depth and the metabolic capacity 
diminishes. However, metabolisation of certain pesticides as organochlorines is proven to be more effective in anaerobic conditions $^{\mathbf{1 4}}$ and thus with specific bacterial collaborative communities named consortia. If coring sediment for organic pollutant investigation is uncommon but not rare, only one paper has attempted to integrate cores and in situ sediment activity (i.e. bioturbation or microbial activity through diagenesis). ${ }^{15}$ They observed that "the increased relative abundance of DDDs in the deposits undoubtedly resulted from reductive dechlorination of DDT, a process that can occur abiotically ( $c f$., citations in Sayles et al., and Boul) or through microbial activity (Esaac and Matsumura). ${ }^{16,17,18}$ The vertical succession of degradation processes induced by the consortia or physico-chemical parameters can be investigated by studying the mineralisation phase, i.e. early diagenesis. Similarly, the quantity and quality of organic matter in sediment could explain the pesticide content.

The first objective of this study was to observe and describe the vertical profile of pre-emergence herbicides for the first time in the sediment. The second was to attribute disappearance to causal processes. The time-scale will provide information on the respective roles of respiration-distinguished consortia or abiotic transformation, especially specific vulnerability to anoxic consortia. The interaction between herbicides on the one hand and quality and quantity of organic matter on the other will be discussed.

\section{Materials and methods}

\subsection{Sampling area}

Sediment samples were collected in the Malause reservoir. This reservoir is situated at the confluence of the Tarn and the Garonne Rivers, in the south-west of France $\left(44^{\circ} 05^{\prime} 00.13^{\prime \prime} \mathrm{N}, 1^{\circ}\right.$ $\left.02^{\prime} 18.47^{\prime \prime} \mathrm{E}\right)$. It is considered to be a major discontinuity along the river continuum (water residence time from 1 to 5 days), resulting in a high sedimentation rate and silting. Shallow water $(<2 \mathrm{~m})$ represents about $20 \%$ of the total area. Two stations, MG and MT (Fig. 1), were chosen in shallow sedimentation areas, under the hydrological influence of the Garonne River and the Tarn River, respectively. The physico-chemical characteristics, pedological evolution and anthropic impact effects in this part of the Garonne basin have been described elsewhere. ${ }^{2,19-21}$ Diagenesis indicators have been investigated at the two stations since Autumn 2004 to qualify and quantify compounds associated with early diagenesis of $\mathrm{OM}$, equilibrium status and, indirectly, the intensity of sedimentation at these locations.

At each study site, one $70 \mathrm{~cm}$-long core was sampled for pesticide analysis. All the equipment was made of glass and stainless steel. Additionally, one core (a $7.5 \mathrm{~cm}$-diameter PVC tube, $40 \mathrm{~cm}$ long) was collected with approximately $15 \mathrm{~cm}$ of surface sediments plus 1-2 L of surface water to measure geochemical profiles.

Comparing pre-emergence herbicides and early diagenesis indicator profiles was preceded by 1 year investigating early diagenesis indicators. Some resulted in approximating enforced processes. Briefly, over this year, (i) bioirrigation molecular diffusion multiplied by a factor ranging from 1 to 4 , (ii) the mean sedimentation rate was $5 \mathrm{~cm} \mathrm{yr}^{-1}$ (Etcheber, personal communication), and (iii) early diagenesis was based on three metabolic pathways: aerobic degradation (in situ relative contribution to total degradation: $49-56 \%$ ), methanogenesis (in situ relative contribution to total degradation: $37-41 \%$ ) and denitrification (relative contribution to total degradation: $8-13 \%$ ). The reduction of iron, manganese and sulfate contributed to less than $1 \%$ of the total according to the early diagenesis model, which must

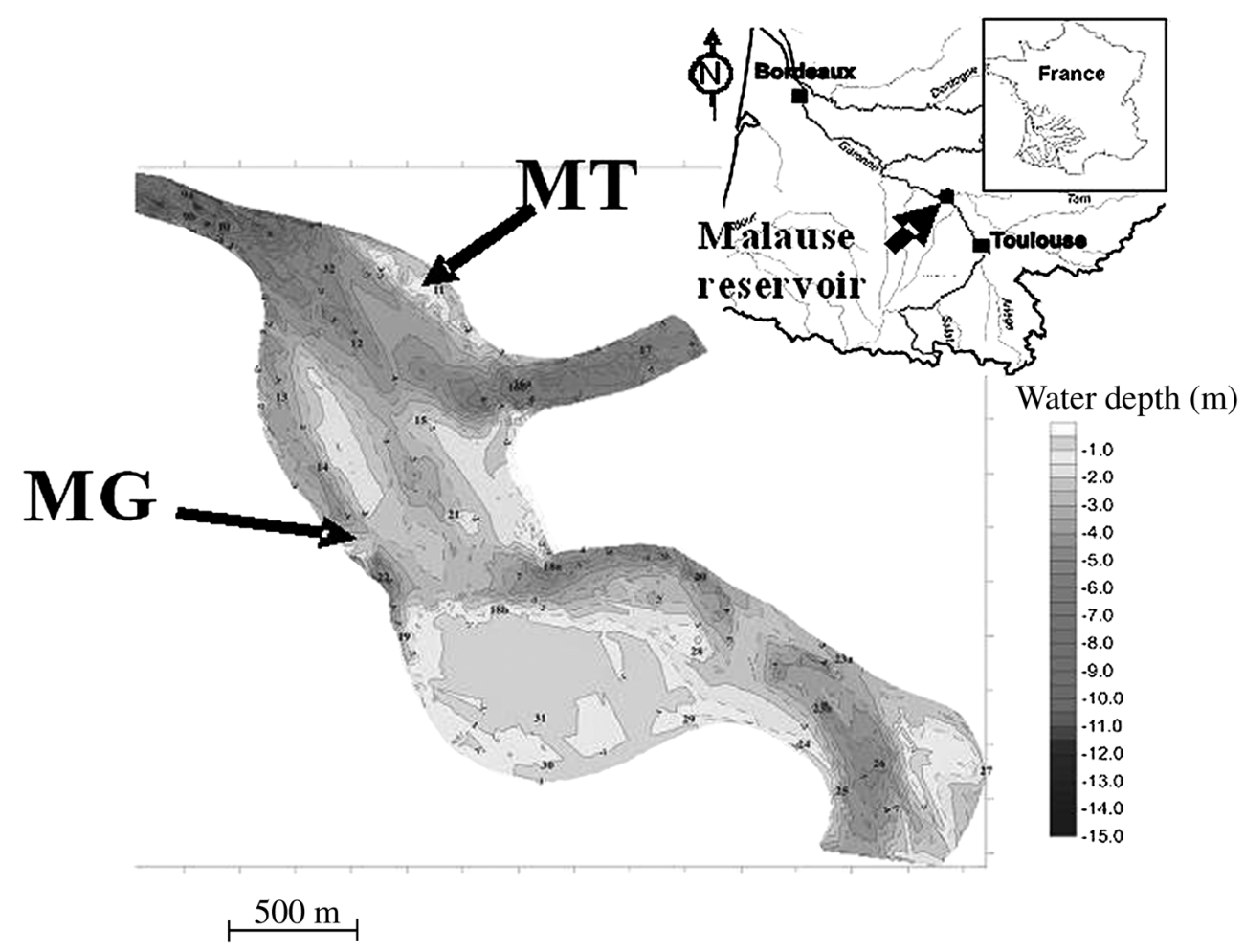

Fig. 1 Location of Malause reservoir and sampling sites of MG and MT coring. 
be taken with caution, but gives an indication. For further information, see Delmotte. ${ }^{22}$

\subsection{Sampling period}

Sediment samples were collected during a winter low-water event corresponding to the beginning of herbicide application and to maximal sedimentation. Samples were collected in March 2006. This was the most pronounced low-water event of the winter so the sediment collected had never been above the water level.

\subsection{Pesticide assay}

2.3.1. Sample treatment. The different sediment fractions were separated according to the methods of the Commission of Oslo and Paris (OSPAR). ${ }^{23-27}$ The components of the dried sediment were separated in an agate mortar and sifted with a 2 $\mathrm{mm}$ mesh (stainless steel sieves from Retsch $\mathrm{GmbH}$ and Co. KG (Haan, Germany) to distinguish and eliminate coarse plant remains and gravel. In practice, coring was performed in sediment known to be free of large obstacles.

The cores were cut into sections: Section 1: $0-0.5 \mathrm{~cm}$, Section 2: $0.5-1 \mathrm{~cm}$, Section 3: 1-1.5 cm, Section 4: 1.5-2 cm, Section 5: 2-3 $\mathrm{cm}$, Section 6: 3-4 cm, Section 7: 4-6 cm, Section 8: 6-8 cm, Section 9: 8-10 cm, Section 10: 10-12 cm and Section 11: 12-14 $\mathrm{cm}$. For certain analyses, Section $12(29-31 \mathrm{~cm})$ and Section 13 $(44-46 \mathrm{~cm})$ were also added. Owing to the small quantities of sediment per section, no distinction was made between fine and coarse fractions. This distinction was made, however, in an earlier study in the same reservoir.,.$^{2,28}$

2.3.2. Sample analysis. All solvents were of analytical grade for pesticide analysis ("Pestipur" by SDS, Peypin, France). Analytical grade anhydrous sodium sulfate was also from SDS. Pesticide standards (Mix 44), prepared by Dr Ehrenstorfer GmbH (Augburg, Germany), were purchased from C IL, SainteFoy-la-Grande, France, for quantifying the herbicides listed in Table 1(b). The reference soil (Eurosoil7) was from SigmaAldrich (St. Louis, MO, USA). The Florisil cartridges used for purification were from Waters Corporation (Milford, MA, USA).

Extraction was performed with a Dionex Accelerated Solvent Extractor (ASE 200) (Dionex, Salt Lake City, UT, USA). Diatomaceous earth (Hydromatrix ${ }^{\circledR}$ ) was from Varian (Palo Alto, CA, USA). ASE extracts were analysed using a TraceGC ultrachromatograph coupled with a TraceDSQ mass spectrometer (GC-MS) from Thermofinnigan (Waltham, MA, USA). Chromatographic SIM conditions have been detailed elsewhere. ${ }^{2}$ Briefly, the splitless mode (injector temperature: $280^{\circ} \mathrm{C}$ ) was set up at an initial temperature of $45{ }^{\circ} \mathrm{C}$. The first step had a temperature increase rate of $35^{\circ} \mathrm{C} \mathrm{min}{ }^{-1}$ up to $180{ }^{\circ} \mathrm{C}$, then a second step at $8{ }^{\circ} \mathrm{C} \mathrm{min}^{-1}$ up to $280{ }^{\circ} \mathrm{C}$ and, finally, a $10 \mathrm{~min}$ plateau at $280{ }^{\circ} \mathrm{C}$. The detection conditions were temperature, $300{ }^{\circ} \mathrm{C}$; EMV, $2600 \mathrm{~V}$.

\subsection{Geochemical profiles}

To determine the geochemical profiles, the cores were cut into ten sections. In each section, part of the sediment was sub-sampled for: (i) Organic carbon assay. The sediment was first freeze-dried and then treated with $\mathrm{HCl}(1 \mathrm{M})$ to remove inorganic carbon. It was subsequently dried at $40^{\circ} \mathrm{C}$. Organic carbon concentrations were determined using a NA 2100 Protein $\mathrm{CHN}$ analyser from CE instruments (Wigan, UK).

(ii) Methane assay. Immediately after slicing, the sediment was placed in a sealed glass container with $10 \mathrm{ml}$ of $\mathrm{NaOH}(0.1 \mathrm{M})$. Methane concentrations were measured using the headspace technique, with a gas chromatograph. ${ }^{29}$

(iii) Nutrient assay. Sediment was centrifuged at $4000 \mathrm{rpm}$ to collect the pore water. Ammonium and nitrate concentrations were measured by flow injection. Sulfate concentrations were measured with a Dionex DX120 chromatograph.

(iv) Double extraction of Chl- $a$ was carried out with acetone and assayed on a Uvikon 930 spectrometer from Kontron Instruments (Plaisir, France). Solute and particulate iron and manganese were quantified following the protocol described in Anschutz et al. ${ }^{30}$

2.4.1 Sample extraction and purification. The pesticide extraction and purification schedule has been explained elsewhere. ${ }^{2}$ Chromatography, in the specific ion mode, was set up at an initial temperature of $55^{\circ} \mathrm{C}$ for $0.5 \mathrm{~min}$. The temperature

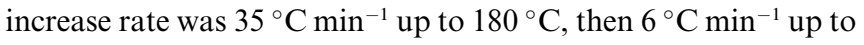
$240{ }^{\circ} \mathrm{C}, 10^{\circ} \mathrm{C} \mathrm{min}^{-1}$ up to $280{ }^{\circ} \mathrm{C}$ and finally a $25 \mathrm{~min}$ plateau at $280{ }^{\circ} \mathrm{C}$.

2.4.2 Statistical analysis. Observations were consolidated by Spearman correlation rank analysis and $\mathrm{R}^{2}$ for $p=0.05$ between early diagenesis indicators and pesticides.

2.4.3 Chemical degradation. Degradation of chemicals, and especially pesticides, could be due to biota. Biodegradation depends on metabolism, directly (consumption of molecules as carbon and energy sources) or indirectly (peripheral pathways which could result from desorption or speciation of metallic cation $^{31}$ ). Mesophile flora is favored by $5-40{ }^{\circ} \mathrm{C}$ and $7-8.5 \mathrm{pH}$ conditions. Actinomycetes are favoured by more acid conditions and dryness. Redox potential around $750-800 \mathrm{mV}$ corresponds to oxic conditions where flora and fauna are theoretically more active. However, studies for halogenated chemicals such as organochlorinated pesticides contradict. ${ }^{32}$ In the same way, considering that rhizosphere favours the growth of bacterial colonies, sampling points in the present study were not performed in water grass beds.

Hydrolysis is the fundamental phenomenon occurring in an abiotic area and is the basis of many enzymatic processes. Photodegradation could occur in the water column but should be rarer for sediment-associated molecules.

$\mathrm{s}$-Triazines are proven to be heterogeneously sensitive to abiotic hydrolysis, moderately increased by the presence of microbes, colorants or solvents. ${ }^{33}$ The process involved is dealkylation of lateral chains.

Substituted ureas are moderately sensitive to photodegradation and hydrolysis. However, the presence of microbes could significantly increase N-demethylation and hydroxylationdemethoxylation. ${ }^{34}$ Photodegradation could directly induce hydrolysis, dehalogenation, dealkylation and deamination, ${ }^{33}$ especially in the presence of colorants and chlorophyll. 
Table 1 Compounds associated with early OM diagenesis studied in pore water and herbicides studied in sediment

(a) Compounds associated with early OM diagenesis

Organic carbon

Chl- $a$

$\mathrm{NH}_{4}{ }^{+}$

$\left(\mathrm{NO}_{2}^{-}+\mathrm{NO}_{3}^{-}\right)$

$\mathrm{SO}_{4}{ }^{2-}$

$\mathrm{CH}_{4}$

(b) Herbicides studied in sediment

Atrazine

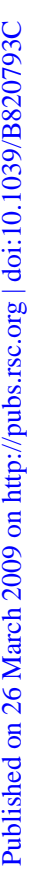

Cyanazine

Simazine

Terbuthylazine<smiles>CCNc1nc(Cl)nc(NC(C)C)n1</smiles>

Metabenzthiazuron<smiles>CNC(=O)N(C)c1nc2ccccc2s1</smiles>

Metobromuron<smiles>CON(C)C(=O)Nc1ccc(Br)cc1</smiles>

Linuron<smiles>CON(C)C(=O)Nc1ccc(Cl)c(Cl)c1</smiles>

Isoproturon<smiles>CC(C)c1ccc(NC(=O)N(C)C)cc1</smiles>

Metazachlor<smiles>Cc1cccc(C)c1N(Cn1cccn1)C(=O)CCl</smiles>

Metolachlor

Hexazinone<smiles>CCNc1nc(Cl)nc(NC(C)CC)n1</smiles><smiles>COCC(C)NC(=O)CCl</smiles><smiles>CN(C)c1nc(=O)n(C2CCCCC2)c(=O)n1C</smiles><smiles>CCc1cccc(C)c1C</smiles> 
Chloracetanilides are more sensitive to biodegradation than hydrolysis.

The study aims to assess the microbial role in the in situ degradation of the herbicides in sediment, where microbes encounter various carbon and energy sources and where microbial consortia could be segregated by their electron acceptor.

\section{Results and discussion}

\subsection{Herbicide concentrations}

The results are presented in Table 2. The MT core (from the Tarn branch) presented a significantly higher average herbicide contamination $(3.52 \pm 2.77 \mu \mathrm{g} / \mathrm{g})$ than the $\mathrm{MG}$ core (from the Garonne branch) $(0.51 \pm 0.36 \mu \mathrm{g} / \mathrm{g})$, i.e. a ratio of 6.90 between MT and MG. s-Triazines contributed more to MG contamination $(97 \pm 71 \%)$ than to MT contamination $(67 \pm 57 \%)$. Substituted ureas contributed less to MG contamination ( $3 \pm$ $2 \%$ ) than to MT contamination ( $31 \pm 41 \%)$. Anilides contributed less to MG contamination $(0.15 \pm 0.16 \%)$ than to MT contamination $(0.08 \pm 0.14 \%)$. s-Triazines were more concentrated in MT sediment (4.9 times the MG values), as were substituted ureas and anilides (64.6 and 90 times the MG values, respectively).

The most abundant herbicide in MG cores was terbuthylazine (with an average concentration of $0.23 \pm 0.13 \mu \mathrm{g} / \mathrm{g}$ ), cyanazine $(0.13 \pm 0.09 \mu \mathrm{g} / \mathrm{g})$ and DEA $(0.11 \pm 0.31 \mu \mathrm{g} / \mathrm{g})$. These first three molecules accounted for $93.6 \%$ of the herbicide contamination in MG sediment. Atrazine, metobromuron, monolinuron and metazachlor presented undetectable concentrations. MG4 was the most polluted layer $(1.41 \mu \mathrm{g} / \mathrm{g})$, whereas MG12 contamination was undetectable. The highest levels of contamination were found under the surface samples and above the deep samples. Average s-triazine $(0.49 \pm 0.36 \mu \mathrm{g} / \mathrm{g})$ was higher than substituted urea $(0.02 \pm 0.02 \mu \mathrm{g} / \mathrm{g})$ or anilide $(0.00 \pm 0.00 \mu \mathrm{g} / \mathrm{g})$ contamination. On the basis of occurrence, s-triazines $(56.1 \%)$ were found more frequently than anilides $(50.0 \%)$ and substituted ureas $(34.8 \%)$.

The most abundant herbicide at MT was DEA (with an average concentration of $1.384 \pm 1.69 \mu \mathrm{g} / \mathrm{g}$ ), followed by isoproturon $(1.007 \pm 1.439 \mu \mathrm{g} / \mathrm{g})$ and cyanazine $(0.82 \pm 0.72 \mu \mathrm{g} / \mathrm{g})$. These first three molecules accounted for $91.0 \%$ of the total herbicide contamination of MT sediment. Atrazine and metobromuron presented undetectable concentrations. MT5 was the most contaminated layer $(9.30 \mu \mathrm{g} / \mathrm{g})$ and MT11 the least contaminated $(0.24 \mu \mathrm{g} / \mathrm{g})$. As in $\mathrm{MG}$, the most contaminated sections were the sub-surface sections, the uppermost and lowermost sections presenting the lowest concentrations. Average s-triazine contamination $(2.427 \pm 2.00 \mu \mathrm{g} / \mathrm{g})$ was greater than substituted urea $(1.10 \pm 1.45 \mu \mathrm{g} / \mathrm{g})$ or anilide $(0.00 \pm 0.01$ $\mu \mathrm{g} / \mathrm{g})$ contamination. On the basis of occurrence, s-triazines $(66.7 \%)$ were found more frequently than anilides $(36.4 \%)$ and substituted ureas $(36.1 \%)$.

Vertical herbicide profiles (Fig. 2) did not present a regular global tendency, for either increases consecutive to herbicide accumulation or decreases associated with herbicide transformation. Numerous herbicide profiles appear random. However, some seem to follow the same pattern. MT isoproturon, MG

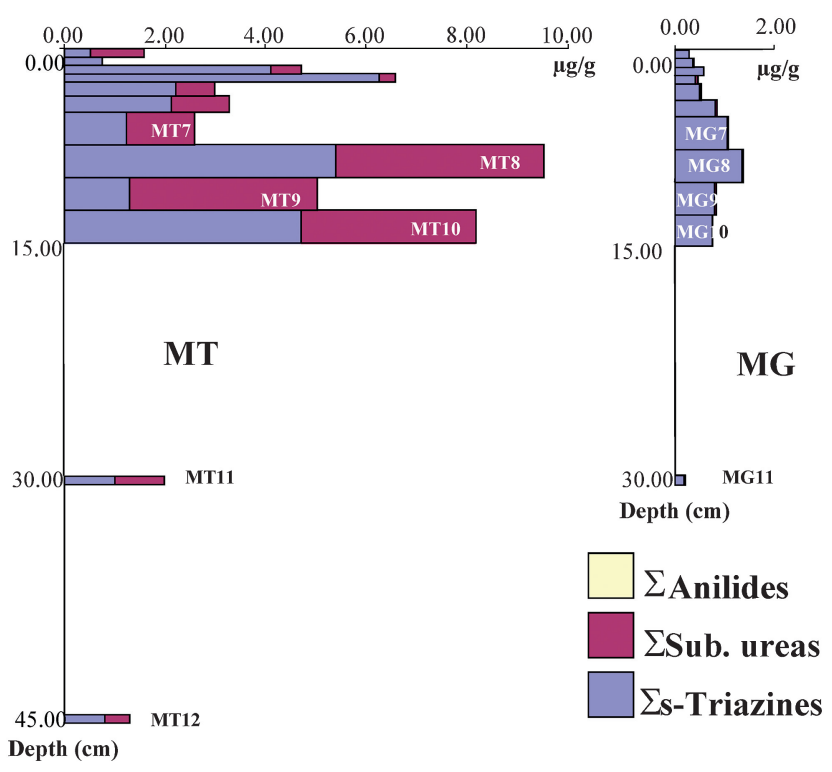

Fig. 2 Vertical configuration of sediment contamination.

linuron, metoxuron and DEA presented maximal concentrations for sections 5-6 and decreasing concentrations below and above. MG and MT simazine, MG cyanazine and MG terbuthylazine presented two high levels: one at section 3 and one at section 9: on either side of a minimum at section 6 . The only regular profile was found for MT sebuthylazine, increasing near the surface.

No global depletion tendency could be inferred from the vertical herbicide profile. The random nature of the herbicide results could be due to the time patterns of the introduction of contaminated sediment into Malause reservoir depending on both flood events and herbicide spreading. The lack of correlation is probably most attributable to in situ sampling: each molecule could be biodegraded and the residual stock depends on (i) residue input, and therefore on practices and hydrology (ii) (bio)degradability of each molecule in the Malause context and bacterial flora and (iii) aging on particles. Nevertheless, incomplete profiles could be regarded as an interpretative handicap since they correspond to field reality only available from in situ experiments. The absence observed could result from complete degradation or desorption during events (bacterial bloom, massive sediment handling, a chemical or physical event such as anoxia or drought) or changes in agricultural practices.

However, the levels of herbicide residues are correlated to the average remanence of each family. The MG and MT sampling sites are located just before the area where the Garonne and Tarn waters mix. Because of the layout of the reservoir, sediment at the MG site is sampled after the transformation process, whereas the MT core is at the beginning of the process. A previous study ${ }^{34}$ indicated that degradation was the major process of herbicide transformation.

In the MG core, s-triazines, known to be more remanent than the two other families, dominated more than in the MT core.

Metoxuron and terbuthylazine are the only molecules strongly or exclusively associated with urban use. In France, the herbicide terbuthylazine is used on grapes, apples and, to a lesser extent, maize and sorghum. The herbicide metoxuron is exclusively used 


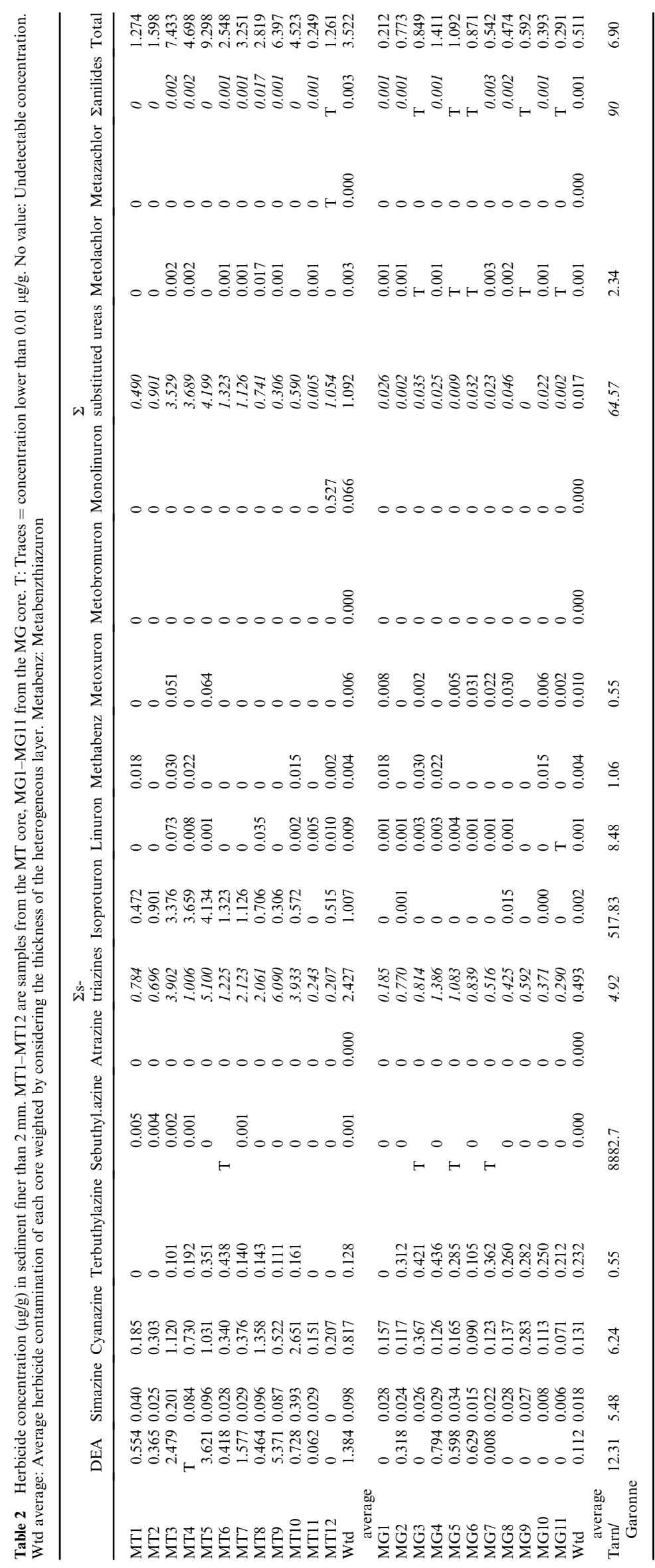


in France for non-agrarian applications (Dosanex C). The fact that these herbicides were found in greater proportions in the Garonne part of Malause reservoir suggests that they were released by the Toulouse urban area (population, 1 million), $80 \mathrm{~km}$ upstream.

\subsection{Mineralisation of organic matter}

The results are shown in Fig. 3. Concentrations of organic carbon varied between 1 and $2 \%$ within the MG core. The MT core exhibited higher concentrations and variations, with most values lying between 2 and $3 \%$, with a maximum of $3.9 \%$ at $9 \mathrm{~cm}$. Neither the MG nor the MT profiles showed any trend in the vertical distribution of organic carbon, suggesting low degradation rates and/or high transport intensities that would have homogenised the concentrations at greater depths.

Chl- $a$ is considered a marker of fresh organic matter. ${ }^{35}$ Within the MG core, Chl- $a$ was present from the surface to $5 \mathrm{~cm}$ below, with concentrations reaching $15 \mu \mathrm{g} \mathrm{g}^{-1}$ at $2 \mathrm{~cm}$. This subsurface peak may result from a discontinuous input of algae at the surface. Conversely, the profile of Chl- $a$ in the MT core presented an exponential decrease in concentration, from approximately 30 $\mu \mathrm{g} \mathrm{g}^{-1}$ near the surface to $1 \mu \mathrm{g} \mathrm{g}^{-1}$ at $9 \mathrm{~cm}$. This suggests a higher input of fresh organic matter in the MT sediment than in the MG sediment. Nevertheless, maximal degradation of Chl- $a$ (and of fresh organic matter) occurred in the first $4 \mathrm{~cm}$ in both sediment cores. Using a conventional ratio of 50 between Chl- $a$ and carbon, ${ }^{36}$ we can estimate that fresh organic carbon (labile fraction) accounted for less than $10 \%$ of the total organic carbon, confirming the non-labile nature of the majority of the organic matter in the sediments. This explains the absence of a vertical trend in the organic carbon profiles.

This can be confirmed by analysing the nutrient and methane profiles. First, the nitrate concentration dramatically decreased in the first centimetre of sediment, from $200-300 \mu \mathrm{M}$ to $1 \mu \mathrm{M}$ at 1 $\mathrm{cm}$. This indicates a high denitrification activity in the first centimetre. Hence, we can speculate that the aerobic mineralisation of organic matter occurs within the first $0.5 \mathrm{~cm}$ and that denitrification is the first anoxic metabolism after the aerobic degradation in the vertical succession of mineralisation pathways. ${ }^{37}$ Ammonium production occurs from the surface to the bottom of the sediment cores, with higher concentrations at MT (maximal value about $6000 \mu \mathrm{M}$ in the MT core versus $1300 \mu \mathrm{M}$ in the $\mathrm{MG}$ core). The profiles adopt a conventional shape of increasing concentrations with depth, the lowest values being found in the first few centimetres due to the release of ammonium
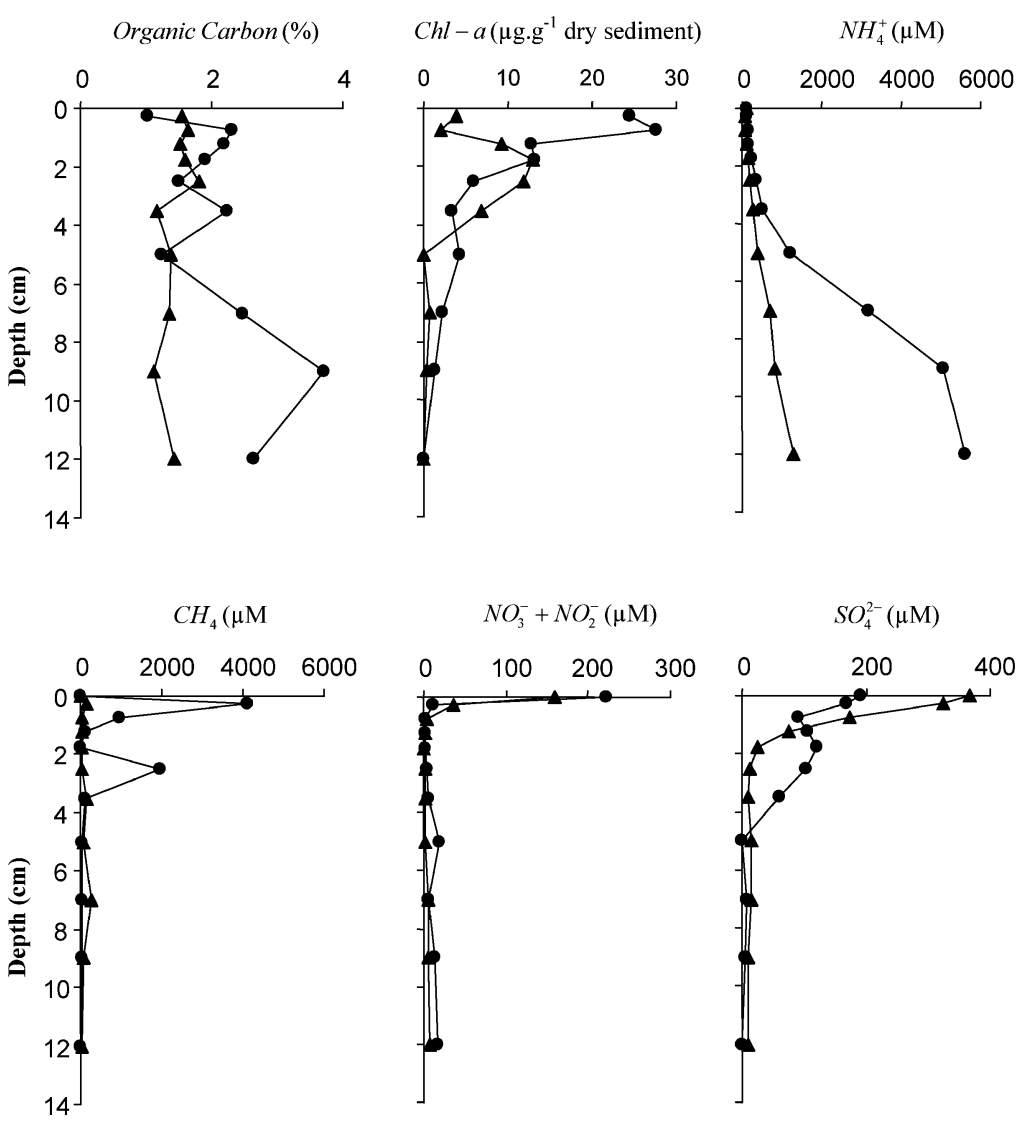

- MT

\ $\quad$ MG

Fig. 3 Vertical profiles of various dissolved and solid compounds associated with the mineralization of organic matter in sediments. MT denotes the Tarn core and MG denotes the Garonne core. 
into the water column by diffusion and bioirrigation. ${ }^{22}$ Likewise, methane production was much higher in the MT core, with two subsurface peaks at 0.5 and $3 \mathrm{~cm}$. Concentrations reached 5000 $\mu \mathrm{M}$ just below the surface, whereas the maximal concentration was approximatemy $300 \mu \mathrm{M}$ at $\mathrm{MG}$. This indicates a higher degradation activity in the MT sediments; particularly in the first $4 \mathrm{~cm}$. Confirming data from 1 year, manganese and iron reduction processes are minor degradation processes. ${ }^{38}$ The relative contribution of iron and manganese reduction in the total MO degradation accounts for less than $1 \%$ according to the results from the application of a multi-component reactive transport model that describes the early diagenesis of the MO in sediments. ${ }^{38}$ Finally, sulfate concentrations decreased in the first $4 \mathrm{~cm}$ of the sediments as a result of the sulfate reduction processes. Porosity and granulometry characteristics are compiled in Table 3.

To sum up, the analysis of these geochemical profiles (Table 4) shows that: (i) organic carbon is generally refractory in sediments; (ii) degradation mainly occurs in the first $5 \mathrm{~cm}$ of the sediment column; (iii) the metabolic activity is higher in the MT sediments than in the MG sediments, probably because of a recent input of fresh organic matter, as shown by the higher Chl- $a$ concentrations; (iv) anoxic organic matter mineralisation is dominant below $0,5 \mathrm{~cm}$. Moreover, the presence of Chl- $a$ at depth in the MT core suggests high transport intensity. Since bioturbation is low at low temperatures $\left(5{ }^{\circ} \mathrm{C}\right.$ here $),{ }^{38}$ strong sedimentation may have occurred as a result of recent hydrological events. Over the years, an average sedimentation rate of $5 \mathrm{~cm} \mathrm{yr}^{-1}$ is given for the Malause reservoir (Etcheber, personal communication). Sedimentation rate is a mean including deposition and erosion events. This implicit component of the sediment rate should be taken into account for the interpretation. Coring sites were selected as sheltered deposition sites, coves buffering an erosion event. Considering the previous year, a twice-weekly survey has been carried out during the previous year, assuming the lowness of deposition

Table 3 Physical characteristics of sediment, porosity (without dimension data) and granulometry depending on depth

\begin{tabular}{lclll}
\hline Ref. & Depth $(\mathrm{cm})$ & Porosity & $<63 \mu \mathrm{m}(\%)$ & $>63 \mu \mathrm{m}(\%)$ \\
\hline MT-1 & $0-0.25$ & 0.78 & 95.94 & 4.06 \\
MT-2 & $0.25-0.75$ & 0.74 & 96.39 & 3.61 \\
MT-3 & $0.75-1.25$ & 0.73 & 96.58 & 3.42 \\
MT-4 & $1.25-1.75$ & 0.72 & 96.65 & 3.35 \\
MT-5 & $1.75-2.5$ & 0.72 & 96.62 & 3.38 \\
MT-6 & $2.5-3.5$ & 0.65 & 97.69 & 2.31 \\
MT-7 & $3.5-5$ & 0.63 & 98.07 & 1.93 \\
MT-8 & $5-7$ & 0.64 & 97.76 & 2.24 \\
MT-9 & $7-9$ & 0.60 & 98.51 & 1.49 \\
MT-10 & $9-12$ & 0.61 & 98.39 & 1.61 \\
MG-1 & $0-0.25$ & 0.85 & 94.64 & 5.36 \\
MG-2 & $0.25-0.75$ & 0.78 & 95.33 & 4.67 \\
MG-3 & $0.75-1.25$ & 0.74 & 95.82 & 4.18 \\
MG-4 & $1.25-1.75$ & 0.73 & 96.01 & 3.99 \\
MG-5 & $1.75-2.5$ & 0.69 & 96.45 & 3.55 \\
MG-6 & $2.5-3.5$ & 0.65 & 97.20 & 2.80 \\
MG-7 & $3.5-5$ & 0.65 & 97.13 & 2.87 \\
MG-8 & $5-7$ & 0.68 & 96.61 & 3.39 \\
MG-9 & $7-9$ & 0.69 & 96.45 & 3.55 \\
MG-10 & $9-12$ & 0.58 & 98.36 & 1.64 \\
\hline
\end{tabular}

and erosion events. This is an average value that can vary greatly because of massive deposition and erosion events. Nevertheless, experiments since 2004 support the $5 \mathrm{~cm} \mathrm{yr}^{-1}$ estimate.

\subsection{Interaction diagenesis/herbicide profile}

Herbicides resist the biologically active layers - the first $5 \mathrm{~cm}$, i.e. year of sedimentation-without major consequences from the multiple processes occurring there. This evident indifference to biological activity is supported by the lack of statistical relationship between early diagenesis indicators and herbicides. This is not the case for other molecules, such as organochlorine pesticides, known to be sensitive to various abiotic conditions and to the different microbiological consortia. ${ }^{15-18,39,40}$ No herbicide profile seems to depend on depth (except MT sebuthylazine), illustrating the independence of the early diagenesis parameters from the herbicide profile.

The random profile of the pesticides does not support homogenisation or any single explanatory phenomenon, thereby opposing the assumption of intense transport within the sediment, at least for herbicides. It therefore seems that degradation by the biota (bacteria and invertebrates involved in bioturbation) does not have a great impact on these herbicides, whatever the chemical family considered. However, the weakness of bioturbation's impact on the herbicide profile could result from the high intensity of sedimentation, quickly burying any fresh deposits. The study of sites with more limited sedimentation could help reach a firm conclusion.

The herbicides considered have a much longer in situ lifespan than suggested by in vitro experiments. Considering the MT core, MT12 presented a total herbicide concentration $(1.261 \mu \mathrm{g} / \mathrm{g})$ corresponding to $13.6 \%$ of the maximum observed (9.298, MT5). Assuming constant pesticide input (which is false, since the use of these molecules has shown a decreasing trend in recent years; UIPP, personal communication), these two layers separated by $42 \mathrm{~cm}$ of sediment settling at a rate of $5 \mathrm{~cm}$ per annum led to a 3-year estimate. MT includes organic matter more recently introduced into the reservoir and MG contained already largely degraded organic matter: the labile carbon concentration was higher in MT than in MG. The same was found for herbicides, suggesting that they are adsorbed on labile organic matter and not on refractory substrates. Likewise, methanogenesis is more intense in MT. In MG, degradation was less intense probably because of the lower level of labile carbon. The slow residual activity clearly illustrates that the MG sediment is more refractory, i.e. degradation is more advanced, than in MT sediment. This is supported by the presence of a decreased abundance of substituted ureas and anilides in MG than in MT. However, the generally accepted relationship between the level of labile organic carbon and the herbicide concentration should also take the halflife into consideration. Substituted urea and anilide MT/MG ratios are clearly higher than s-triazine $\mathrm{MT} / \mathrm{MG}$ ratios, confirming the higher remanence of s-triazines compared to the other two.

Early diagenesis indicators showed that the sediment had an undisturbed structure. Moreover, degradation of labile organic matter (half-life $2-3$ months) is faster than degradation of the adsorbed herbicide (half-life 2-3 years). 
Table $4 \mathrm{Mn} \mathrm{HCl}$ and $\mathrm{Fe} \mathrm{HCl}$ : oxides and iron and manganese hydroxide profiles, including reactive and nonreactive fractions

\begin{tabular}{lcrrlr}
\hline Ref. & Depth & $\begin{array}{l}\mathrm{Mn}^{2+} \\
(\mu \mathrm{mol} / \mathrm{L})\end{array}$ & $\mathrm{Fe}^{2+}$ & $\begin{array}{l}\mathrm{Mn} \mathrm{HCl} \\
(\mu \mathrm{mol} / \mathrm{g})\end{array}$ & $\mathrm{FeHCl}$ \\
\hline Surface & -2 to 0 & 2.40 & 4.28 & & \\
MT-1 & $0-0.25$ & 9.96 & 2.90 & 4.28 & 99.56 \\
MT-2 & $0.25-0.75$ & 22.86 & 12.84 & 4.60 & 80.72 \\
MT-3 & $0.75-1.25$ & 23.05 & 6.92 & 4.28 & 91.59 \\
MT-4 & $1.25-1.75$ & 34.29 & 26.06 & 4.31 & 90.28 \\
MT-5 & $1.75-2.5$ & 44.06 & 33.11 & 3.67 & 85.52 \\
MT-6 & $2.5-3.5$ & 38.40 & 11.33 & 3.76 & 94.56 \\
MT-7 & $3.5-5$ & 47.55 & 11.21 & 3.46 & 95.38 \\
MT-8 & $5-7$ & 43.71 & 11.71 & 4.31 & 100.75 \\
MT-9 & $7-9$ & 57.42 & 12.59 & 3.44 & 67.09 \\
MT-10 & $9-12$ & 85.22 & 31.98 & 3.62 & 90.39 \\
Surface & -2 to 0 & 3.49 & 0.00 & & \\
MG-1 & $0-0.25$ & 16.53 & 0.00 & 8.20 & 143.23 \\
MG-2 & $0.25-0.75$ & 20.93 & 4.15 & 5.56 & 131.61 \\
MG-3 & $0.75-1.25$ & 20.57 & 3.15 & 4.52 & 144.97 \\
MG-4 & $1.25-1.75$ & 17.63 & 2.39 & 4.35 & 140.57 \\
MG-5 & $1.75-2.5$ & 26.99 & 4.91 & 4.11 & 124.98 \\
MG-6 & $2.5-3.5$ & 36.43 & 6.67 & 3.73 & 163.87 \\
MG-7 & $3.5-5$ & 58.11 & 12.21 & 3.76 & 145.73 \\
MG-8 & $5-7$ & 121.13 & 95.31 & 5.01 & 120.22 \\
MG-9 & $7-9$ & 95.63 & 71.26 & 5.61 & 104.82 \\
MG-10 & $9-12$ & 53.92 & 147.30 & 4.57 & 141.77 \\
\hline
\end{tabular}

This remanence of a pesticide stock in sediment could generate a huge amount of pesticide able to be restituted through a sudden event (flood, dredging, dam failure...). ${ }^{40-42}$

\section{Conclusion}

The present study indicates the indifference to biological activity of herbicides adsorbed onto sediment. Given the long global half-life observed ( 3 years), the transformation measured must stem from physicochemical processes (hydrolysis). In contrast, the general literature reports relatively high lability for these three herbicide families. Although the degradation is much slower than hoped for, transformation does occur, as confirmed in older sediment from the MG core, which presented less herbicide, the decrease being most pronounced for the substituted ureas and anilides.

\section{Acknowledgements}

We thank Gwenael Abril, Pierre Anschuzt and Jonathan Deborde who helped in measuring methane, iron and manganese in the sediments. Sebastien Delmotte benefited from a grant from French Ministry of Research and Higher Education (MESR).

This study was conducted as part of the GISECOBAG, Programme P2 "Mid-Garonne River", and was supported by funds from CPER and FEDER (grant no. OPI2003-768) of the MidiPyrenees Region and Zone Atelier Adour Garonne (ZAAG) of PEVS/CNRS-INSUE. Special thanks are extended to Francis Dauba for his helpful technical assistance.

\section{References}

$1 \mathrm{M}$. Gavrilescu, Fate of pesticides in the environment and its bioremediation, Engineering in Life Sciences, 2005, 5(6), 497-526.

2 D. A. Devault, G. Merlina, P. Lim, J. L. Probst and E. Pinelli, Multiresidues analysis of pre-emergence herbicides in fluvial sediments:
Application to the mid-Garonne river, Journal of Environmental Monitoring, 2007, 9, 1-9.

3 D. MacKay and A. Fraser, Bioaccumulation of persistent organic chemicals: Mechanisms and models, Environmental Pollution, 2000, 110(3), 375-391.

4 D. J. H. Phillips, B. J. Richardson, A. P. Murray and J. G. Fabris, Trace metals, organochlorines and hydrocarbons in Port Phillip Bay, Victoria: A historical review, Marine Pollution Bulletin, 1992, 25(5-8), 200-217.

5 R. V. Thomann, J. P. Connolly and T. F. Parkerton, An equilibrium model of organic chemical accumulation in aquatic food webs with sediment interaction, Environmental Toxicology and Chemistry, 1992, 11, 615-629.

6 A. E. Carey, G. B. Wiersma, H. Tai and W. G. Mitchell, Pesticides in soil. Organochlorine pesticide residues in soils and crops of the corn belt region, United States 1970, Pesticide monitor journal, 1973, 6(4), 369-376.

7 R. Frank, M. Holdrinet and H. E. Braun, Organochlorine insecticides and PCBs in sediments of Lake St. Clair (1970 and 1974) and Lake Erie (1971), Science of the Total Environment, 1977, 8(3), 205-227.

8 E. W. Wolff, Signals of atmospheric pollution in polar snow and ice, Antarctic Science, 1990, 2(3), 189-205.

9 J. B. Brett, UK Atlantic Margin Environmental Survey: Introduction and overview of bathyal benthic ecology, Continental Shell Resource, 2001, 21(8-10), 917-956.

10 J. P. Abraham, F. W. Whicker, T. G. Hinton and D. J. Rowan, Inventory and spatial pattern of $137 \mathrm{Cs}$ in a pond: a comparison of two survey methods, Journal of Environmental Radioactivity, 2000, 51(2), 157-171.

11 D. Broman, C. Näf and H. Axelman J Pettersen, Time trend analysis of PAHs and PCBs in the northern Baltic proper, Chemosphere, 1994, 29(6), 1325-1331.

12 Z. Chen, B. Xing, W. B. McGill and M. J. Dudas, $\alpha$-Naphthol sorption as regulated by structure and composition of organic substances in soils and sediments, Canadian Journal of Soil Science, 1996, 76(4), 513-522.

$13 \mathrm{~J}$. G. Jones, Microbes and microbial processes in sediment, Philosophical Transactions of the Royal Society of London. A., 1985, 315, 3-17.

14 N. L. Wolfe, R. G. Zepp, D. F. Paris, G. L. Baughmann and R. C. Hollis, Methoxychlor and DDT degradation in water: rates and products, Environmental Science \& Technology, 1977, 11, 10771081 .

15 R. P. Eganhouse, J. Pontolillo and T. J. Leiker, Diagenetic fate of organic contaminants on the Palos Verdes Shelf, California, Marine Chemistry, 2000, 70(4), 289-315.

16 G. D. Sayles, G. You, M. Wang and M. J. Kupferle, DDT, DDD, and DDE dechlorination by zero-valent iron, Environmental Science \& Technology, 1997, 31, 3448-3454.

17 E. G. Esaac and F. Matsumura, Metabolism of insecticides by reductive systems, Pharmacology and Therapeutics, 1980, 9, 1-26.

$18 \mathrm{H}$. L. Boul, DDT residues in the environment - a review with a New Zealand perspective, New Zealand Journal of Agricultural Research, 1995, 38, 257-277.

19 D. Etchanchu and J. L. Probst, Evolution of the chemical composition of the Garonne river during the period 1971-1984, Hydrologic Science Journal, 1988, 33, 243-256.

20 F. Dauba, S. Lek, S. Mastrorillo and G. H. Copp, Long-term recovery of macrobenthos and fish assemblages after water pollution abatement measures in the river Petite Baïse (France), Archives of Environmental Contamination and Toxicology, 1997, 33, 277-285.

21 R. A. Hutagalung, P. Lim, A. Belaud and T. Lagarrigue, Global effects of an agglomeration on fish typology of a river: case of the Garonne in Toulouse (France), Annals of Limnology, 1997, 33, 263279.

22 Please provide reference.

23 G. Umlauf and R. Bierl, Distribution of organic micropollutants in different size fractions of sediment and suspended solid particles of the River Rotmain, Z. Wasser-Abwasser-Forsch, 1987, 20, 203-209.

24 OSPAR- Strategy for a program of evaluation and continuous monitoring (JAMP) (in French), 2005; 2003-22.

25 J. P. Gao, J. Maguhn, P. Spitzauer and A. Kettrup, Distribution of pesticides in the sediment of the small Teufelsweiher pond (Southern Germany), Water Research, 1997, 31(11), 2811-2819. 
26 J. P. Gao, J. Maguhn, P. Spitzauer and A. Kettrup, Sorption of pesticides of the Teufelsweiher pond (Southern Germany). II: Competitive adsorption, desorption and aged residues and effect of dissolved organic carbon, Water Research, 1998, 32(7), 2089-2094.

27 A. W. Leonard, R. V. Hyne, R. P. Lim, K. A. Leigh, J. Le and R. Beckett, Fate and toxicity of endosulfan in Namoi River water and bed sediment, Journal of Environmental Quality, 2001, 30, 750759 .

28 D. A. Devault, M. Gérino, C. Laplanche, F. Julien, P. Winterton, G. Merlina, F. Delmas, P. Lim, J. M. Sánchez Pérez and E. Pinelli, Accumulation or elimination of herbicides by reservoirs, Sci. Total Environ., 2009, DOI: 10.1016/j.scitotenv-2008.12.064.

29 G. Abril and N. Iversen, Methane dynamics in a shallow non-tidal estuary (Randers Fjord, Denmark), Marine Ecology, Progress Series, 2002, 230, 171-181.

30 P. Anschutz, B. Sundby, L. Lefrançois, G. W. Luther and A. Mucci, Interactions between metal oxides and species of nitrogen and iodine in bioturbated marine sediments, Geochimica et Cosmochimica Acta, 2000, 64, 2751-2763.

31 R. A. Larson and E. J. Weber, Reaction Mechanisms in Environmental Organic Chemistry, Lewis Publishers, Boca Raton, Florida, 1994, p. 433.

32 M. M. Häggblom, I. D. Bossert, Dehalogenation - Microbial Processes and Environmental Applications, Kluwer Academic Publishers, Norwell, MA, 2003, 520 pp.

33 H. D. Burrows, L. M. Canle, J. A. Santaballa and S. Steenken, Reaction pathways and mechanisms of photodegradation of pesticides, Journal of Photochemistry and Photobiology B: Biology, 2002, 67, 71-108.
34 R. Calvet, E. Barriuso, C. Bedos, P. Benoit, M.-P. Charnay, $\mathrm{Y}$. Coquet, Les pesticides dans le sol - Conséquences agronomiques et environnementales, Editions France Agricole, Paris, 2005, 637 pages (in French).

35 M.-Y. Sun, R. C. Aller, C. Lee and S. G. Wakeham, Effects of oxygen and redox oscillation on degradation of cell-associated lipids in surficial marine sediments, Geochimica et Cosmochimica Acta, 2002, 66, 2003-2012.

36 S. E. Jorgensen, Handbook of Environmental Data and Ecological Parameters, Pergamon Press, 1979, New York, 1100 pp.

37 P. N. Froelich, G. P. Klinkhammer, M. L. Bender, N. A. Luedtke, G. R. Heath, D. Cullen, P. Dauphin, D. Hammond, B. Hartman and V. Maynard, Early oxidation of organic-matter in pelagic sediments of the Eastern Equatorial Atlantic-suboxic diagenesis, Geochimica Cosmochimica Acta, 1979, 43, 1075-1090.

$38 \mathrm{~S}$. Delmotte $\mathrm{PhD}$, Benthic invertebrates' role in organic matter transformation into the sediment, Thesis, University of Toulouse III, 2007, 282 pp, (in French).

39 J. Foght, T. April, K. Biggar and J. Aislabie, Bioremediation of DDTcontaminated soils: A Review, Bioremediation Journal, 2001, 5(3), 225-246.

40 W. Stumm, Chemistry of the Solid-Water Interface: Processes at the Mineral-Water and Particle-Water Interface inNatural Systems. Wiley-Interscience, Hoboken, NJ, 1992, 448 pages.

41 A. A. Koelmans and L. Prevo, Production of dissolved organic carbon in aquatic sediment suspensions, Water Research, 2003, 37, $2217-2222$.

$42 \mathrm{~S}$. Carpentier, Balance and impact of sediments deposition in the river basin of the Seine river, Thesis, Paris University of Paris XII-Val de Marne, 2002, 210 pp, (in French). 